\title{
ACTIVITY AND PASSIVITY: CLASS AND GENDER IN THE CASE OF THE ARTIFICIAL HAND
}

\section{By Clare Stainthorp}

A young lady, daughter of a distinguished nobleman, had through congenital malformation a hand which was minus all its fingers and a great part of its palm; the thumb, however, remained; she had had the deficiency made up since her childhood by a wooden piece of mechanism which presented every visible appearance of the natural hand, and with which, having a perfect thumb, she could perform naturally all the duties of an ordinary hand. When, however, she reached the age at which she was to be presented, and was to take that position in society for which her rank fitted her, it became obvious that at dances and elsewhere, whenever she gave her hand to anyone, its artificiality would be detected, not only by its woodeny hardness, but also by a point which is equally perceptible, its lowness of temperature (for artificial hands are always cold and below the bodily temperature, and feel, to use a popular expression, as the "hand of death"). Having thought the matter over I tried the following plan: I procured the skeleton of a hand the same size. I then, by a very carefully and beautifully made system of jointing, articulated the various bones quite accurately and naturally. I had them fitted on to a leathern glove-sheath that exactly enclosed the malformed part and then caused a special kind of felted material to be so modelled over the bones that the actual shape of the malformation plus the glove was that of the natural hand, and was a fellow to the one of the opposite side. Nothing remained but to have the contained bones precisely copied in ivory, because there was naturally an irresistible objection to wearing the actual bones of a defunct human being; and when this was done the hand was complete.

The result was perfectly successful. The felt had the exact feel of flesh, it took the temperature of the body, and the bones could be felt through just as they are in the natural hand.

—Henry Robert Heather Bigg, Artificial Limbs (1885)

THIS ARTICLE ANALYZES THE TENSION between the active, present body and the absent, passive body in this medical case study, presented by doctor and prosthetist Henry Robert Heather Bigg in his 1885 book Artificial Limbs and the Amputations which Afford the Most Appropriate Stumps in Civil and Military Surgery. I reproduce Bigg's account in its entirety because, to date, Artificial Limbs has not been digitised, although it is held at around a dozen 
academic libraries in the UK and USA respectively. Bringing attention to and providing a close reading of a source not previously discussed academically sheds new light on the way the disabled body was read by medical professionals in the second half of the nineteenth century. In addition, I consider Bigg's narrative rendering of this unique case study alongside several contemporary sources, including memoirs, novels, short stories, and journal articles. In doing so, I identify how assumptions made by Bigg about the (disabled, female, privileged) hand mirror and echo those in the wider cultural sphere. The sensing hand is an instrument of will, and the creation of such a prosthesis troubles the dynamics of active and passive, touching and touched that Pamela K. Gilbert has identified as crucial to nineteenth-century discourses surrounding the hand. By designing and making this prosthesis, Bigg exerts his professional and masculine agency to make the woman's body assume the position of something beheld rather than embodied.

The first section of this article reads Bigg's case study and its immediate context in terms of the assumed role of the medical practitioner and the anonymous woman for whom he creates the prosthesis. The following section discusses the specifics of the hand Bigg created, noting the conflicts inherent in his pursuit of a "natural hand." Pertinent here is the relationship between hands and religious anxieties about bodily perfection, and the question of deceiving by design. This article concludes with a discussion of the cultural significance of Bigg's use of the phrase the "hand of death" when describing a traditional artificial hand in the context of nineteenth-century fiction.

\section{Contexts}

VANESSA WARNE HAS ARGUED for the importance of examining prostheses critically, stating that "[s]imultaneously material and symbolic, artificial legs are artifacts of a culture and its views on class, industry, technology, and disability, but they are also artifacts of the daily lives of disabled Victorians" ("Artificial Leg" 33). In my discussion of the artificial hand, I seek to address similar concerns. Rather than approaching the prosthesis as an artefact, however, I focus on text, identifying and interrogating the designer-maker's assumptions surrounding the device's functional requirements. As a result, what follows is not a discussion of the object itself, but rather what Bigg's description of this prosthesis tells us about a medical professional's perception of this woman's needs.

This approach stems partially from necessity, since it has not been possible to locate an extant version of this unusual prosthetic hand. More pertinently, however, Bigg's decision to anonymise the subject and focus on perceived functionality rather than personal testimony makes it unfeasible to consider the specifics of this young woman's experiences of disability and prosthesis. The reader is given no indication of how it felt to be the congenitallydisabled daughter of a nobleman who required increasingly elaborate prostheses to pass; these avenues are simply not left open by his text. ${ }^{1}$ Bigg's obituary in the Lancet (1746) notes that he "was very kind to his patients, took keen interest in their welfare, and was beloved in return"; however, the removed perspective with which Bigg describes the dilemma of the young woman's artificial limb frames the case study as a professional challenge rather than an opportunity to improve an individual's quality of life. He states that her prosthesis was "perfectly successful" and "so entirely satisfactory that twice subsequently [he] constructed the same form of hand" for other individuals "each time with complete success" (Artificial Limbs 76, 77). ${ }^{2}$ But it is unclear how far this success relates to the woman's 
practical experience, the focus being placed exclusively on his technical achievement from an outsider's perspective; Bigg is preoccupied with mimicking what "[w]hen we grasp anyone's hand... we experience," and the phrase "we feel" is repeated five times in the following two sentences (76-77).

The "we" of Bigg's narrative is clearly aligned with the doctor and his imagined readership, the able-bodied medic. This rhetoric has been highlighted by Diane Price Herndl as continuing to exist in the medical profession. Indeed, while she is concerned with twentyfirst-century medical humanities scholars, her identification of an "assumption of the absolute barrier between 'we' normal providers and 'the other,' 'abnormal,' 'deformed' patient, who lives in some other context from "us"' is equally relevant to Bigg's writing (596). Through this binary model "we" becomes active and visible while the individual with a disability is pushed into a passive role, her/his identity existing only at the peripheries of the text. Indeed, half way through Bigg's case study the young woman disappears entirely and is replaced by a fragmented body that is transformed from "malform[ed]" to "complete." Significantly, we are not informed whether this prosthesis impacted positively upon the woman's life overall. This differs from other case studies in Artificial Limbs where the active bodies of men and working-class women are described in terms of a renewed ability: they are now able to write, crochet, play the violoncello, and (in the case of a Navy commander) "hang bodily" from rigging with their new limbs $(A L 100,79,83)$. This observation forms the basis of my argument that Bigg's framing of this case study is intrinsically linked to his assumptions about class and gender.

The perspective on disability articulated by medical texts has been under-researched in nineteenth-century studies, although work has been done on the visual and textual representation of prosthetic limbs in manufacturers' catalogues, and surgeon Charles Bell's 1833 treatise The Hand. ${ }^{3}$ In contrast to these sources, which demonstrate the commercial register and the popularisation of natural theology respectively, Artificial Limbs establishes the viewpoint of a professional writing for other professionals. While such a text might be expected, and even professes, to offer a dispassionate assessment of disablement and rehabilitation, Bigg writes in a broadly conversational tone. As such, Artificial Limbs often falls into narrative and colloquialisms that reveal assumptions about the "deformed" body; what is - and is not - said is indicative of the social and cultural construction of disability and the hand in nineteenth-century Britain.

In Lennard J. Davis's terms, Bigg's case study provides an insight into the "hegemony of normalcy" that was "enforced in public venues" in nineteenth-century Britain (44). Viewing a body that violates cultural norms from a medical perspective, considering its parts' simultaneous presence and absence, forces us to see it in an alternative light, to evaluate, in Bigg's words, the "essentials of the natural limb in detail, and show what it is that has to be reproduced" ( $A L$ 30). As Bigg's framing of this case-study demonstrates, for an upper-class nineteenth-century woman these needs went well beyond (or indeed, fell well short of) the practical and functional in an attempt to reproduce the hand's multiple social and cultural resonances.

\section{"[H]e devoted himself to the mechanical treatment of deformities"}

HENRY HEATHER RoberT BIGG (1853-1911) was a military surgeon, who followed his father (1826-81, also named Henry Heather Bigg) into a professional life specialising in 
amputations and artificial limbs. ${ }^{4}$ Neither figure has been considered in more than passing reference within the history of medicine or disability studies, despite being among the most respected such professionals in nineteenth-century Britain. ${ }^{5}$ Bigg Sr. wrote several books including On Artificial Limbs, their Construction and Application (1855), which has many similarities to his son's 1885 book; notably Bigg Sr. considered a significant failing of his career to be that "touch instantly decides between the real hand and its counterfeit" (62). Thirty years later, Bigg claims "satisfactorily to have solved" this problem in creating the hand upon which this article focuses ( $A L 75)$.

In Artificial Limbs, Bigg discusses which operations yield the best stumps for receiving an artificial limb and goes on to "show what it is that has to be reproduced, as well as the perfection with which such reproduction can be effected in the present day" (30). Artificial Limbs was aimed at, and probably received, a relatively small professional readership; it was self-published and only ran to one edition, however it was favourably reviewed in the British Medical Journal as "likely to be of real service" which "will well repay careful study by surgeons" ("Review" 1173, 1172). This review, which prints Bigg's main recommendations for surgical improvements, indicates that his opinions were respected and probably would have been put into practice.

Throughout Artificial Limbs assumptions are made about what is "natural" in relation to the human body. Bigg Sr. remarked that "[d] eformity ..., as a rule, is a chronic source of discontent and unhappiness, and too commonly it gives occasion to petty insult, annoyance, and neglect" (Orthopraxy 8). In like manner Bigg approaches disability as something to be fixed or hidden, his role being the creator of prostheses that make an imperfect body whole, unremarkable, and therefore "normal." This rhetoric of (ab)normality was far from unusual during the nineteenth century, and Rosemarie Garland-Thomson has identified the impact of such vocabulary: "We say things like "bodies that violate the normative standards and expectations of bodily form and function' not to obfuscate but rather to clarify by insisting that readers do not fall back on essentialist definitions of disability as inferior embodiment" ("Feminist Disability Studies" 1558). Nuances such as this fall well outside Bigg's linguistic register, and indeed that of most Victorians, but this absence is nevertheless telling. In his case study, the subject's selfhood and embodiment is almost entirely neglected in favour of promoting a narrative of passing; Bigg seeks to bestow naturalness to an unnatural body. As Davis describes in Enforcing Normalcy, ideas surrounding the "normal" or "natural" in relation to the human body and people's responses to disability are "socially conditioned, politically generated" (13). As a consequence, this article uses the vocabulary employed by Bigg when discussing the non-normative body on the understanding that doing so provides an insight into received ideas that attached themselves to the body, materially and symbolically.

Bigg's remark, "I procured the skeleton of a hand the same size," is indicative of how these assumptions shape his narrative; under the surface of this comment lie ingrained beliefs about the fragmentation and commodification of the body. Ruth Richardson in Death, Dissection and the Destitute observes that by the nineteenth century "in medical circles, market terminology was being applied to human corpses apparently without embarrassment" (55). Upon the passing of the Anatomy Act in 1832, the bodies being made available for medical study shifted from being those of criminals and those disinterred by "resurrectionists" to those of individuals who were "unclaimed" after dying in hospitals and workhouses (193215). Bigg's procurement of a skeletal hand would have been, therefore, through such channels, either directly (as a surgeon living on Wimpole Street in London he was in 
close proximity to the dissecting rooms at the Middlesex Hospital and Medical School) or indirectly through a medical supplier. ${ }^{6}$ The "procured" bones likely belonged to a workingclass woman, and this point is the first example of enforced absence I wish to highlight since Bigg's medical rhetoric absolutely obscures such individuals' identity and, indeed, humanity. His framing of this case study thus entails a dual excision: the individual that (almost certainly unwittingly) donated her hand, and the disabled subject who wore the resultant prosthesis. Both women are cast as props with which Bigg demonstrates his considerable professional skill.

Constructing a prosthesis by articulating a skeletal hand and enclosing it in felt is surprising, necessitating a counter-intuitive process of transformation. Bigg seems very pleased with his solution; that he buried an actual dead hand within his most life-like prosthesis delights him. His jocular description of replacing the bones with ivory because there is "an irresistible objection to wearing the actual bones of a defunct human being" implies that it is a concession to the objections of the young lady or a quirk of polite society. ${ }^{7}$ Bigg does not acknowledge the hand's cultural status as a marker of identity, which undoubtedly led to anxiety over figuratively transplanting another person's hand (and attendant selfhood) onto a different body. ${ }^{8}$ Some context for his approach is provided in the introduction to Artificial Limbs: Bigg asserts that earlier prosthetic devices were crude reproductions because the maker "did not pick as it were the body to pieces.... He only copied vaguely by the light of external structure" ( $A L$ 30). Here Bigg also emphasizes why the customary lack of communication between surgeon and prosthetist is problematic, and how his medical training (which was uncommon, most makers being artisans) fostered his ability to design life-like artificial limbs. ${ }^{9}$ The resultant tension between the natural and the false, the living and the dead, underlies Bigg's framing of his case study and its implications for understanding the function and resonances of such a prosthesis.

\section{"A hand of this kind need not be used... when the wearer is not being seen"}

BIGG BEGINS BY NOTING that since childhood the young woman's "situation" was covered "by a wooden piece of mechanism which presented every visible appearance of a natural hand; and with which, having a perfect thumb, she could perform naturally all the duties of an ordinary hand." This utilitarian prosthesis functioned adequately, but entry into society is deemed to necessitate a hand that feels natural to others. Implied here is her new "duty" to establish partnerships at "dances and elsewhere" through which she might, both literally and figuratively, "g[i]ve her hand to anyone." Bigg acknowledges earlier in the chapter that "one performs a multitude of the actions of everyday life with the hand"; however, many of these are disregarded in this instance because a prosthetic "of this kind need not be used in the house, or when the wearer is not being seen" $(A L 72,80)$. This device is only required when she is subject to the "eugenic gaze" whereby people identify "meaning in normative and nonnormative features," thus enabling the young woman to present herself in a fashion considered acceptable to observers (Davis 46).

Notably, this young woman's deficiency is one of the few completely anonymous case studies in Artificial Limbs, the individual being described only in terms of her gender and class. In contrast, many of Bigg's other patients are either named outright or are referred to by initials, their case-studies often accompanied by a portrait sketch including the prosthetic limb. The bestowal of anonymity is particularly telling because it is also applied to a 
"young University man" and a "Rugby school-fellow" (AL 70-71, 88-90). Significantly, the disabilities of these young men and the nobleman's daughter are all described as impediments to gaining their desired place in society. Both men believed their vocation to be in the Church but were prevented from being ordained as a result of a "wasted" arm with "diminutive hand" and an amputated arm respectively, breaching a church ruling that to be ordained one must be bodily perfect. The hand was particularly important in such a context because, as discussed by Peter Capuano in Changing Hands, many in the nineteenth century identified the hand as a divine mechanism; as a result, "the metaphorical absence of God's hand [was] figured by the literal absence of a human hand" (60). Nonetheless, Bigg reports that a bishop agreed to ordain both as long as they had prosthetic arms that meant their "natural shape [was] completely restored and could satisfactorily perform various religious rites" ( $A L$ 90). Incredibly, the "University man" chose to have his semi-functional but "unpleasantly unnatural" "abortive member" amputated in order to be fitted with a prosthesis that made him capable of "unconspicuous and proper performance" of church duties (70). For these two cases, as with that of the young woman, Bigg writes in terms of "mechanically remed[ying]" and masking each "misfortune," anonymity being granted to maintain this concealment (90).

Warne has argued that an "unwillingness to be identified as a user of an artificial limb" was extremely common, particularly for women ("Upper-Class Amputees" 88). She writes in relation to photographs from an artificial limb manufacturer's catalogue in which women turn their face from the camera or obscure it with an upheld magazine in order to elude the gaze that identifies bodily difference. In contrast, Sue Zemka has described nineteenth- and early twentieth-century instances of men who used artificial hands choosing to meet this gaze in photographs staged to promote their prosthetic solutions. The acceptance or rejection of anonymity arises from each individual's navigation of a variety of social pressures and can be nuanced in various ways. For example, although they remain anonymous, Bigg allows the men to retain an active role by describing them actively engaged in their vocation one concludes an "infant could be safely held in baptism" ( $A L 90)$. Similarly, the women in the catalogue photographs exert agency, making an active gesture to hide their identity. In contrast, the young woman in Bigg's case study lacks agency; she is written out of the narrative so that his ingenious prosthetic hand can take centre stage, the author having decided to make her disabled body a passive object.

Furthermore, the requirements of prosthetic functionality are clearly marked by gender. Compare Bigg's focus on natural appearance for the young woman to a case where a "gentleman" had lost his thumb in an accident; although they share their anonymity and class status, no mention is made of concealing the man's disability from others. Instead Bigg's goal is to create a prosthesis that restores "that refinement of feeling and motion that performance on [the violoncello] required" (79). Bigg also references Captain George Webb Derenzy's preoccupation with mechanizing himself in the autobiographical manual Enchiridion: A Hand for the One-Handed (86). Whilst this text is from 1822, Bigg's inclusion of it indicates its relevance over sixty years later. Derenzy was not interested in semblances of naturalness, instead he developed customised attachments to fit into a wrist-plate, increasing his independence and improving his quality of life:

I have been induced to devote a considerable portion of my time and thoughts to the contriving and perfecting of a set of instruments which shall enable the possessor of them to dispense with 
the attendance of a servant, or that attention from a friend, which would otherwise be absolutely necessary. (Enchiridion 11)

Derenzy's "enthusiasm" for mechanising his body for functionality chimes with Erin O'Connor's work on the gendering of prostheses for maimed American Civil War soldiers $(A L 86)$. She concludes that "[i]n order to salvage shattered ideals of manliness, Victorians developed prosthetics that could build fractions of men into the capable composite entities we would now identify as cyborgs" ("Fractions of Men" 775). O'Connor is interested in how men attempted to rebuild their sense of self and finds that through prostheses they morphed into man-machines; "prosthesis engineers a fiction of physical wholeness," and for working men it allowed disability to effectively disappear (745). The case studies in Artificial Limbs support this assertion; the male body is conceived by Bigg as labouring and functional (even if not of the labouring classes). Conversely, the young woman is provided with a specifically feminine prosthesis designed to construct a passive self (reactive not proactive), receptive to the gaze and touch of others. For Bigg, the feminine body requires a prosthesis that functions to trick the eye and hand into perceiving a perfect physical specimen. It does not facilitate independence; instead, the woman with a disability is effectively rendered less able than she had been with her previous wooden version. I contend, however, that this urge for anonymity is more complex than a gender binary and that class is also strongly implicated in deciding who requires and receives such anonymity.

Bigg Sr. addresses this issue, noting that "in the higher classes of life, it becomes requisite to conceal the loss, in addition to obtaining a certain amount of usefulness," and it is the mechanician's task "to hide any bodily deformity from the eyes of the world" (On Artificial Limbs 44). Bigg Sr.'s observation echoes the rhetoric David D. Yuan identifies in Oliver Wendell Holmes's 1863 essay “The Human Wheel, Its Spokes and Felloes," whereby “polite society does not wish to see certain realities" and visible disabilities " are never tolerated under the chandeliers"" (qtd. in Yuan 75). The case study offered by this American text shares a significant characteristic with the younger Bigg's case study, for it is "with the dawning of sexual possibility that the weight of Palmer's aesthetic disability begins to be felt" and the young man is deemed to require a more sophisticated prosthesis than his existing "peg leg" (Yuan 80). These are the principle motivations for Bigg's identification of a need for a society lady to own a prosthetic hand that not only looks and perhaps moves naturally, but feels natural too. This issue is not mentioned in any of Bigg's other case studies: for the military and working classes "facility and comfort" is paramount ( $A L 100)$. Bigg uses this phrase in relation to Mrs Robertson of Dundee, the only other female patient in his book, whose quadruple amputation is particularly unusual regarding functionality because her working-class background necessitated that she could support herself financially as well as physically. ${ }^{10}$ Bigg goes on to describe her quite extraordinary artificial lower-arms and hands, which enabled her "to crochet with great facility and precision ... and write with most perfect legibility" (100). Although a woodcut of Mrs Robertson with and without her prostheses is printed alongside, there is no textual mention of a need for perceived naturalness; instead, the focus is on her ability to walk and maintain herself "by crochet work" (100). The practicality Bigg attributes to Mrs Robertson's prostheses stands in stark contrast to the "natural" feeling, non-labouring prosthesis that enabled a young woman to pass in social situations, facilitating acquaintances with potential marriage partners wishing to "take her hand." 
This young woman of noble birth "had through congenital malformation a hand which was minus all of its fingers and a great part of its palm; the thumb, however, remained" (76). The nature of her disability differs from the majority of other cases described by Bigg, in which limbs were lost through industrial accidents, military injuries, or infection. It also contrasts with much recent scholarship, which has primarily focused on the first two of these causes when analysing the impact of disability and prosthesis in the nineteenth century. As a result, this elision means that in their discussion of artificial limbs O'Connor, Zemka, and others have been concerned with the act of recreating rather than creating body parts. While we do not know whether the young woman's case was an incident of hereditary disability, the potential for such assumptions to be made about an aristocratic family may have provided additional impetus for hiding it. Indeed Martha Stoddard Holmes discusses how as "a Victorian cultural sign, disability pointed not only backward, to parental transgression and defect, but even more urgently forward, to future generations" (Fictions of Affliction 68). For example, the entry on marriage in Thomas Andrew's 1842 Cyclopedia of Domestic Medicine and Surgery points to anxieties surrounding the female body, stating that one "should not marry a woman ... feeble, or affected with any deformity or disease" (337).

The development of eugenics, which arose from the application of Darwinian evolution to human society by theorists such as Francis Galton (and later Cesare Lombroso), compounded this view. Such readings of disability are bound to preconceptions about the role of the body in terms of gender and also class; from this perspective, the procreative role of wife and mother, conceived as default for Victorian femininity, is something from which a woman with a disability is excluded. Indeed Holmes identifies how, despite an "increasing richness" in their characterisations and place in marriage plots throughout the nineteenth century, "disabled women characters almost never become biological parents" (Fictions of Affliction 6). Although Bigg does not specifically reference such concerns, this woman's anonymity provides an insight into perceived social prejudices about physical disability, the procreative role of women, and the importance of the marriage market when assessing female value.

Bigg is preoccupied with facilitating the woman's ability to "take that position in society for which her rank fitted her." His foregrounding of "rank" brings into question how, from his perspective, disability was regarded by different levels of society. In the previous century, William Hay claimed in Deformity: An Essay (1755) that the upper classes treated individuals with disabilities more respectfully than did their working-class counterparts, reporting "[1]aughter in the lower sort: while their Betters... are restrained by good Sense and good Breeding from such an insult" (34). While etiquette may have curtailed overtly offensive behaviour towards their social-equals, Holmes has uncovered an alternative narrative regarding disability, class, and community. Through the personal testimonies in Henry Mayhew's London Labour and the London Poor (1851), she traces evidence of support networks, for example the blind boot-lace seller asserts that "blind people in the streets mostly know one another" and make a concerted effort to acquaint themselves with those they do not (qtd. in Holmes, "Autobiographical Narratives" 39). Holmes notes that "[t]his sense of community... is far less evident in the life writings of wealthier Victorians with physical impairments," suggesting that a "strategy of "passing' was promoted and necessitated" ("Autobiographical Narratives" 39; 43, n.2). This is illustrated by the blind MP Henry Fawcett (1833-84) who "pointedly spoke as if he could see, and advised others to "do what you can to act as though you were not blind"' (43, n.2). Fawcett's attitude to disability informs upon Bigg's case study, since the deception of acquaintances 
about one's true nature is the guiding motivation for this prosthetic hand. The need for a body to tend towards the normal proves a social requisite, enforced by the power structure represented by both Bigg, as a doctor, and the woman's family and social circle, as members of the upper classes.

\title{
"[T]he arm, and more especially the hand, are subject to constant critical inspection."
}

THE FOLLOWING REFLECTION ON THE MOTIF of the female hand in Victorian literature by Helena Michie identifies how a hand deemed to be abnormal challenges cultural expectations of a young woman's social and romantic behaviour:

\begin{abstract}
Victorian novels are frequently about women's hands: hands that stand for hearts, and hands that are won and offered by themselves. The hands that are offered with hearts, that represent in themselves something higher, constitute one of the centers of value in the nineteenth-century novel. They form a synecdochal chain where the heart represented by the hand is in itself a synecdoche for more obviously sexual parts of the body that enter into a heroine's decision about whom to marry. Asking for a hand is an entrance into the female body, the touch of a hand frequently the first touch between lovers. The disembodied hand, the hand without the heart and whatever it is that the heart itself stands for, is, in the terms of many Victorian novels, an unacceptable fragmentation of the female body. (98)
\end{abstract}

For this chain of association (from hand, to heart, to sex) to be subverted by disability implies that it may not just be the hand that is a "malformed part," undermining the young woman's ability to participate in expected courtship rituals at "dances and elsewhere."

Nineteenth-century norms of female dress pushed the localisation of the erotic to the peripheries of the body, the hand being one such site. In addition, as the most liminal part of the body it exists at the threshold between self and other, its form (even when gloved) always available for visual scrutiny and accessible to be grasped by stranger, acquaintance, or friend. This boundary position places a prosthetic hand in a very different context to an artificial leg, which can be hidden almost entirely from public view and interaction. Bigg identifies the difference between clothed artificial legs and "the arm, and more especially the hand, [that] are subject to constant critical inspection" and possess "the most refined sensibility of any part of the body" ( $A L$ 72). While the hand might be thought of as an inherently active body part, the female hand can also be cast in a passive role that endures the scrutinising gaze of others; it is this facet of communication that Bigg seeks to enable, the natural-feeling prosthesis providing visual and tactile markers of normality for those who might wish to take her hand.

Despite successfully recreating these aspects of the hand, Bigg laments that the smooth skin, unbroken nails, and soft palms that are markers of social position and femininity cannot be successfully imitated: "by no known process can the texture or colour of the human skin be reproduced" (77). He admits that "if sight is to be deceived" the artificial hand must be gloved, and to maintain an illusion of wholeness she must cover the unblemished hand too, rendering her unable to communicate her status through the symbolic refinement of her hands (77). That this surface denotes character and class is central to Richard Beamish's successful 1843 treatise The Psychonomy of the Hand; or The Hand as Index of Mental Development (which drew on the work of Casimir Stanislas D'Arpentigny); Capuano discusses how this type of publication encouraged people to associate "the material features of their hands with the social components of their identities" (Changing Hands 127). While the 
natural-feeling prosthetic hand is intended to enable the young woman to pass in social situations, it nevertheless undermines her ability to participate in this form of encoded communication, there being the caveat that a prospective husband would have to be informed of her disability before she removed her gloves in his presence.

The fundamental tension inherent in Bigg's reproduction of naturalness is that, although the young woman's ability to touch others is facilitated by his craftsmanship, the prosthesis does not counteract the lack of sensation, so she cannot feel whether it is being reciprocated. From this perspective her artificial hand is designed to function in a manner closer to a glass eye, rather than having the practical use of traditional prosthetic hands. Historically, these facial prostheses "have been concerned more with the minimization and concealment of defects than they have with the replacement of function" and so "the development of artificial eyes was of principal benefit not to the prosthetic wearer, but to other people, because it was designed to deflect attention and prevent revulsion" (Handley 97; Eyre 110). Just as an artificial eye is intended to deceive sight but cannot see, this prosthetic hand deceives touch but cannot feel. Bigg's conception of a natural-feeling hand is therefore only applicable from the perspective of others; the woman cannot feel naturally using it, and Bigg does not engage with this lack. William A. Cohen has shown how nineteenth-century connections between the senses and the way individuals understand the self, soul, and mind lie at the heart of "how people are imagined to inhabit their bodies" (23). The prosthetic hand, thus, disrupts this model of sensory experience and, consequently, undermines the agency associated with personhood.

Of additional importance is the loss of autonomy and the unequal power relationship between the prosthesis wearer and the observer-toucher. Bigg expects and encourages scrutiny of the person with a physical disability, it being up to others to decide whether the resultant whole is acceptable. The young woman is removed from the equation. Her sense of self is put in the hands of others (quite literally), mirroring the position of many other marriageable middle- and upper-class young women during the nineteenth century whose families conceived of them as chattel. While I do not wish to negate the role of genuine feeling between individuals seeking marriage in the nineteenth century, Bigg nonetheless undertakes the challenge of making this prosthesis for the whole family, not just the young woman; if the hand does not offer comfort and utility, how far can it truly be said to be for her benefit? Such class and gender implications can be read into Bigg's rhetorical choices: the young woman is a passive figure who does not personally request the new prosthetic hand; instead, upon reaching "the age at which she was to be presented... it became obvious that at dances and elsewhere" the artificiality of her existing wooden hand "would be detected." This contrasts with descriptions elsewhere in Artificial Limbs in which men with disabilities actively approach Bigg as an expert who can create prosthetic limbs to fit their specifications.

Raymond Tallis, in his wide-ranging anthropological and philosophical study of the hand, contemplates the communication inherent in touching hands, which "encompasses a multitude of sins and good deeds, a thousand silent speeches, dozens of different modes of togetherness" (111). Similarly, Bigg asserts that "[t]here can be actual language in the pressure of a hand" ( $A L$ 72). It is this that the young lady is deemed unable to participate in without a prosthetic replacement that feels "natural" to others (and even with it she remains unable to comprehend any reply). Bigg is concerned therefore with "deceiving the sense of touch of other persons when the hand is grasped or shaken," and yet this creates a problematic 
scenario in which the woman must deceive by design in order to prevent someone reading a deceptive personality into her inert hand (75). Bigg proclaims that "it was impossible by touch to distinguish it from a perfectly natural hand," something that O'Connor has dubbed an "ethics of deception" ( $A L$ 77; "Fractions of Men" 768). This is the "superficial logic of prosthetics" that insists it is not who or what you are, but what you seem, that matters, an attitude evident in artificial limb advertisements throughout the second-half of the nineteenth century (Raw Material 136). Writing principally in relation to injured soldiers, O'Connor highlights that " $\mathrm{t}] \mathrm{he}$ truly reassembled man was thus a consummate dissembler," and the same holds true for others who attempted to conceal the ways in which their bodies strayed from expected norms ("Fractions of Men" 769). This type of deception feeds a vicious cycle of popular prejudice against disability, forcing individuals to either display their other-ness or fear discovery as having attempted to hide this.

Indeed, Bigg's preoccupation with variations of the word "natural" encapsulates the tension between his rejection of artificiality in relation to an observer's perception of the woman's prosthesis and his belief that persons with a disability must deceive by design to hide aspects of their physical self. He states that the problem with the young lady's original prosthesis was that "whenever she gave her hand to anyone, its artificiality would be detected"; although this refers to the literal nature of a wooden hand, artificiality of character is also implied. Pertinent here is the pseudo-science of physiognomy, which asserted that temperament and character could be read on the body. David Mitchell and Sharon Snyder have highlighted the connection between the practice of physiognomy and perceptions of disability during the Victorian period, because "speculative qualities such as moral integrity, honesty, trustworthiness, criminality ... became available for scrutiny by virtue of the 'irregularities' of the body that enveloped them" (212). Furthermore Gilbert, in her analysis of touch in David Copperfield, has identified how in interpersonal communication a hand's coldness is a deciding factor that either "confirms or contradicts the evidence of the eyes" (9). ${ }^{11}$ The detection of literal artificiality in a handshake is therefore problematic because insincerity of character could be read into its unresponsiveness.

Discussion of deception through prosthesis might imply that individuals with a disability are placed in an active role, whereby they become the "consummate dissembler" ("Fractions of Men" 769). For the young woman in the case study, however, even this limited agency is taken away from her. Bigg's control over the situation ("I tried the following plan.... The result was perfectly successful") positions him in this creative role; Bigg does not recount a case of self-fashioning, instead he describes how as an authority figure he fashioned the disabled body to comply with social norms.

\section{"[T]he 'hand of death'”}

THE FINAL SECTION OF THIS ARTICLE considers how the active/passive dynamic I have identified in Bigg's case study exists in dialogue with Victorian fiction. This dynamic is motivated by the parenthetical aside that steers Bigg's medical case study into the province of imaginative discourse: "(for artificial hands are always cold and below the bodily temperature, and feel, to use a popular expression, as the 'hand of death')." By equating the coldness of a wooden hand with the unresponsive rigidity of a corpse, Bigg highlights the cultural significance of negative associations surrounding an inert hand being attached to a living body. Defining it as a "popular expression" encourages the reader to make more 
wide-ranging connections and, considering it in the context of nineteenth-century fiction, elucidates that anxieties surrounding the active and passive hand are integral to its cultural resonance.

Pat Jalland has argued that the "role of the upper- and middle-class family at the deathbed... assumed greater significance in the nineteenth century because of the increase in affection within the family" (4). The presence of people at the bedside is significant because at the threshold between life and death a person's hands are often grasped, and so the resulting rigidity and coldness that starts in the extremities is one of the first sensations perceived by grieving relatives. In Mary Barton (1848) Elizabeth Gaskell's description of Ben Davenport's death hinges upon this gesture: "he moved his hand gropingly over the covering. They knew what he meant, and guided it to her head.... It rested there with a feeble pressure of endearment.... The hand was a stiff heavy weight" (70; ch. 6). Davenport attempts to communicate in his final moments through the language that resides in the pressure of a hand, which is then transformed into an inanimate object. The resonance of such an event is attested to by illustrations of death-bed scenes that depict a similar tableau, one example being the etching "Death in Old Age, $c .1873$ " reproduced in Jalland's Death in the Victorian Family (plate 3), in which the clasped hands lie at the very centre of the image and thus command our attention. In the context of courtship, such memento mori are particularly unwelcome; however, this image is just one cultural resonance that Bigg sought to avoid when creating this prosthetic hand.

As a motif of Gothic literature, the "hand of death" is also a "wandering, disembodied hand, or its ghostly partner a hand that that reaches unexpectedly from the shadows," as identified by Katherine Rowe in Dead Hands: Fictions of Agency, Renaissance to Modern (111). This study provides a strong foundation for understanding agency in relation to this motif; of particular relevance is the fourth chapter, which discusses the "small but vigorous tradition in the Victorian ghost story" that uses "the severed, disembodied, or ghostly hand" to drive the plot $(111, \mathrm{x})$. Rowe considers this trope primarily in the context of the working-class hand and the way this Gothic motif resonates with social anxieties, specifically the potential for "sudden abruption or collapse of interpersonal distance" and "reversals of control" (112, xi). The links between artificial hands and dead hands are not explored however, and while class is addressed by Rowe, gender is mostly neglected.

The motif of the dead hand is employed frequently in tales of terror to reinforce the idea that an individual's agency can be retained by their physical remains. As well as the palpable coldness identified by Bigg, the severed hand is applicable particularly to the user of an artificial limb because the ability to dismember oneself (which Bigg puns on in the phrase "gave her hand to anyone") resonates strongly with the tropes of the Gothic stories analysed by Rowe. Demonstrating similar anxieties about the activity of a hand assumed to be passive is the device at the climax of George Eliot's novella "The Lifted Veil" (1859), in which the dead individual's final thought is played out through her hands. As a blood transfusion seemingly brings Mrs Archer back to life, she reveals a plot to poison her husband through the reanimation of her vocal cords and "the hand that Bertha had thought for ever still [being] pointed towards her" ("Lifted Veil" 42; ch. 2). Such references inform upon Bigg's use of the phrase "hand of death" to articulate the specific repulsion that he perceives to reside in an interaction with a standard prosthetic hand. Thus, in addition to the uncanny nature of the prosthesis, Bigg's qualms about the idea that such a hand might be attached to "the daughter of a distinguished nobleman" reveal his unwillingness to allow a young woman's hand to 
evoke these dead hands that overturn authority - of society as well as science - and wield their own unexpected agency.

The ghostly hand also appears in less sensational texts, refiguring the hand reaching from the shadows as mortmain, the legal posthumous control exercised by an individual over their property. Eliot's decision to title Book Five of Middlemarch (1874) "The Dead Hand" is paradigmatic of such references as both Casaubon and Featherstone are shown to wield significant influence over the living after their deaths. The physicality of the hand motif is emphasized in Eliot's description of Featherstone finalising his funeral instructions and "chuckling over the vexations he could inflict by the rigid clutch of his dead hand" (Middlemarch 304; bk. 4, ch. 34). Furthermore, Rowe notes that "from the nineteenth century on, mortmain tales characteristically follow amorous plots," giving it additional resonance with Bigg's case study (116). The relationship between mortmain and the prosthetic hand thus centres on anxieties surrounding agency, and the negative connotations of a dead hand being able to carry out the intentions of its owner.

Such fears manifest in Mary Elizabeth Braddon's “The Cold Embrace” (1860), whereby spectral hands belonging to a young woman who has committed suicide after being jilted haunt her unfaithful fiancé with an embrace that is not "ghostly... for it is palpable to the touch" (8). The "icy grasp" of the "cold, deathlike, but O, how palpable" hands exact their revenge by killing the fiancé to fulfil the lovers' promise that death would not part them (10). These dead female hands terrorize a man as they protest against being denied marriage, personal and social fulfilment symbolised by the betrothal ring tangible on the phantom fingers. As identified by Jennifer Bann, ghostly agency in Victorian ghost stories often hinges upon "contrasting a powerless mortal life with the greater possibilities of a spectral one" (677). Bigg's overt unwillingness to let the prosthesis evoke the "hand of death" is not, therefore, just an avoidance of memento mori, it also indicates a resolve to cut off associations of power with the bearer, removing any unexpected agency or ability to compel others. If, as Bann suggests, "[d]eath transforms passivity into action," by shying away from evoking the "hand of death," Bigg reacts also against the cultural echo of ghostly or cursed hands that bypass social expectations of passivity in accordance with gender and class, and in connection with disability (677).

\section{“[M]asterful manipulative power"}

I CONCLUDE WITH A QUOTATION taken from a few pages after this case study in Artificial Limbs. Here, the relatively impractical nature of the natural-feeling prosthetic hand is introduced by Bigg's assertion that in cases of "congenital malformation" individuals develop "masterful manipulative power" in their thumb and palm, but this facility without a prosthesis is only tolerated "in the house, or when the wearer is not being seen" $(A L 80)$. Bigg's rejection of their autonomous volition highlights his aversion to a disabled body part's assertion of its own power and agency. ${ }^{12}$ Furthermore, it demonstrates that what society and the medical profession considered unnatural and malformed could in fact function perfectly naturally. In this way, Bigg concedes that the young woman is disabled only in the eyes of others and it is societal pressures and the prosthesis itself that render her passive.

Mitchell and Snyder, in their seminal essay "Narrative Prosthesis," propose that "[n]arratives turn signs of cultural deviance into textually marked bodies" and that "[p]hysical and cognitive anomalies promise to lend a 'tangible' body to textual abstractions" (209, 205). 
Conversely, in Artificial Limbs it is the physically marked body that becomes abstracted and written out of the text; instead, Bigg focuses on the mechanical prosthesis and the hand that it is intended to replace both physically and symbolically. Yet, the result is much the same. His refusal to engage with the person with a disability as an individual presumes that the woman conforms to relevant stereotypes while avoiding through omission consideration of her lived experience.

My reading of Bigg's case study is not definitive, and more could be said about the identity of this young woman and the extent to which she may have desired a prosthetic hand not immediately detectable by sight or touch. While Bigg's construction of disability, and the needs of a body marked by class and gender, may not have been shared by every surgeon, there exists a need to consider more closely the distinctive voice of nineteenth-century medical professionals communicating with their peers. In this instance, the cumulative assumptions Bigg forces the reader to make about the function of this prosthetic device demonstrates his unwillingness to situate "the daughter of a distinguished nobleman" in anything other than a passive role. Thus, the hand - as object and cultural construct - acts as a synecdoche for her body, as that of both a marriageable woman and an individual with a disability.

\section{University of Birmingham}

\section{NOTES}

Thanks to Ryan Sweet, Rex Ferguson, several anonymous readers, and attendees of the "Victorian Body Parts" conference (hosted by the British Association for Victorian Studies and Birkbeck Centre for $19^{\text {th }}$ Century Studies in 2013) for their invaluable feedback on this research in its various guises.

1. For "passing" see Garland-Thompson, Staring 42.

2. Hereafter cited parenthetically as $A L$.

3. See Mihm's "Prosthetic Technologies in the Nineteenth Century" and Warne's "Artificial Legs and Upper-Class Amputees at Mid-Century" for readings of prosthetic limbs in catalogues. For a discussion of the work of Sir Charles Bell, see Capuano, Changing Hands 42-66, and his $B R A N C H$ article. Research by Wild and Shuttleton into eighteenth-century doctors' private practice correspondence indicates another approach that might be adopted by scholars working on the nineteenth century.

4. For ease of identification, I designate the older Bigg Sr. to distinguish him from his son who wrote Artificial Limbs. All biographical information about both Henry Heather Biggs has been obtained from "Obituary: Henry Robert Heather Bigg" and "Memoirs: Mr Henry Heather Bigg."

5. Zemka references the importance of the Biggs but does not discuss their contributions in depth.

6. I am indebted to Ruth Richardson for her assistance in identifying likely avenues through which Bigg could have bought a skeletal hand.

7. In fact, had the bones been retained they would have been liable to crumble after little use, but this practical caveat is not mentioned by Bigg. I thank Richardson for this observation.

8. Ferguson has remarked upon twentieth-century anxiety surrounding agency and identity in relation to a hand transplant described in Lawrence Durrell's Clea (1960), while Briefel has considered the consequences of using other people's hands as prosthetics (even metaphorically) in the context of race and identity in the nineteenth century.

9. Capuano's BRANCH essay and chapter two of Changing Hands are concerned with the widelycirculated Bridgewater Treatise The Hand and identify how Charles Bell's experience as a surgeon had a similarly important impact upon his views about the hand in a cultural context. 
10. The description is extracted from Orthopraxy, since Elizabeth Robertson was actually one of Bigg Sr.'s patients. The case brought Bigg Sr. a degree of fame, having been reported as "Quadruple Amputation" in British and American newspapers (Morning Post and New York Times) as well as the British Medical Journal. Bigg states that upon her death the four artificial limbs were left to the Royal College of Surgeons Museum in Lincolns Inn Fields; however, the Huntarian archives have no record of this item ( $A L$ 94).

11. Briefel also argues that hands can betray character and shape identities in ways outside of an individual's control (2-16).

12. Capuano draws out the often overlooked literal resonances of "manipulative" powers in chapter four of Changing Hands when discussing Becky Sharp in Vanity Fair.

\section{WORKS CITED}

Andrew, Thomas. A Cyclopedia of Domestic Medicine and Surgery. Glasgow: Blackie and Son, 1842.

Bann, Jennifer. "Ghostly Hands and Ghostly Agency: The Changing Figure of the Nineteenth-Century Specter." Victorian Studies 51.4 (2009): 663-85.

Bell, Charles. The Hand. Its Mechanism and Vital Endowments as Evincing Design. London: William Pickering, 1833.

Bigg, [Henry Robert] Heather. Artificial Limbs and the Amputations which Afford the Most Appropriate Stumps in Civil and Military Surgery. London: The Author at 56 Wimpole Street, 1885.

Bigg, Henry Heather. On Artificial Limbs, their Construction and Application. London: John Churchill, 1855.

- Orthopraxy: the Mechanical Treatment of Deformities, Debilities and Deficiencies of the Human Frame, A Manual. London: J. \& A. Churchill, 1865.

Braddon, Mary Elizabeth. "The Cold Embrace." The Cold Embrace and Other Ghost Stories. Ed. Richard Dalby. Ashcroft: Ash-Tree, 2000. 3-10.

Briefel, Aviva. The Racial Hand in the Victorian Imagination. Cambridge: Cambridge UP, 2015.

Capuano, Peter J. Changing Hands: Industry, Evolution, and the Reconfiguration of the Victorian Body. Ann Arbor: U of Michigan P, 2015.

. "On Sir Charles Bell's The Hand, 1833." BRANCH: Britain, Representation and NineteenthCentury History. Ed. Dino Franco Felluga. Extension of Romanticism and Victorianism on the Net. Web. 7 Sept. 2015.

Cohen, William A. Embodied: Victorian Literature and the Senses. Minneapolis: U of Minnesota P, 2008.

Davis, Lennard J. Enforcing Normalcy: Disability, Deafness, and the Body. London: Verso, 1995.

Derenzy, George Webb. Enchiridion: A Hand for the One-Handed. London: T. and G. Underwood, 1822.

Eliot, George. "The Lifted Veil." The Lifted Veil • Brother Jacob. Ed. Helen Small. Oxford: Oxford UP, 1999. 1-43.

_. Middlemarch. Ed. David Carroll. Oxford: Oxford UP, 1998.

Eyre, Pauline. "Comment from the Field. Transforming Bodies: Prosthetics Seminar." Journal of Literary \& Cultural Disability Studies 5.1 (2011): 109-12.

Ferguson, Rex. "The Literary Hand: Handwriting, Fingerprinting, Typewriting." Critical Quarterly 56.1 (2014): 40-55.

Garland-Thomson, Rosemarie. "Feminist Disability Studies." Signs 30.2 (2005): 1557-87.

- Staring: How We Look. Oxford: Oxford UP, 2009.

Gaskell, Elizabeth. Mary Barton. Ed. Shirley Foster. Oxford: Oxford UP, 2008.

Gilbert, Pamela K. "The Will to Touch: David Copperfield's Hand." 19: Interdisciplinary Studies in the Long Nineteenth Century 19 (2014). Web. 7 Sept. 2015. 
Handley, Neil. "Artificial Eyes and the Artificialization of the Human Face.” Devices and Designs: Medical Technologies in Historical Perspective. Ed. Carsten Timmerman and Julie Anderson. Basingstoke: Palgrave Macmillan, 2006. 97-111.

Hay, William. Deformity: An Essay. London: R. and J. Dodsley, 1755.

Herndl, Diane Price. "Disease versus Disability: The Medical Humanities and Disability Studies." PMLA 120.2 (2005): 593-98.

Holmes, Martha Stoddard. Fictions of Affliction: Physical Disability in Victorian Culture. Ann Arbor: U of Michigan P, 2009.

. "Working (with) the Rhetoric of Affliction: Autobiographical Narratives of Victorians with Physical Disabilities." Embodied Rhetorics: Disability in Language and Culture. Ed. James C. Wilson and Cynthia Lewiecki-Wilson. Carbondale: Southern Illinois UP, 2001: 27-44.

Jalland, Pat. Death in the Victorian Family. Oxford: Oxford UP, 1999.

"Memoirs: Mr Henry Heather Bigg." Institution of Civil Engineers: Obituaries (1882): 317-20.

Michie, Helena. The Flesh Made Word: Female Figures and Women's Bodies. Oxford: Oxford UP, 1987.

Mihm, Stephen, “'A limb which shall be presentable in polite society': Prosthetic Technologies in the Nineteenth Century." Artificial Parts, Practical Lives: Modern Histories of Prosthetics. Ed. Katherine Ott, David Serlin, and Stephen Mihm. New York: New York UP, 2002. 282-99.

Mitchell, David, and Sharon Snyder. "Narrative Prosthesis." The Disability Studies Reader. Ed. Lennard J. Davis. 2nd ed. New York: Routledge, 2010. 205-16.

O'Connor, Erin. “'Fractions of Men': Engendering Amputation in Victorian Culture.” Comparative Studies in Society and History 39.4 (1997): 742-77.

- Raw Material: Producing Pathology in Victorian Culture. Durham and London: Duke UP, 2000.

"Obituary: Henry Robert Heather Bigg." Lancet 16 Dec. 1911: 1746.

"Quadruple Amputation." British Medical Journal 5 Oct. 1872: 390.

"Quadruple Amputation." Morning Post 9 Oct. 1872: 6.

"Quadruple Amputation.” New York Times 27 Oct. 1872: n. p.

"Review: Artificial Limbs and Amputations which Afford Most Appropriate Stumps in Civil and Military Surgery." British Medical Journal 19 Jun. 1886: 1172-73.

Richardson, Ruth. Death, Dissection and the Destitute. London: Routledge \& Kegan Paul, 1987.

Rowe, Katherine. Dead Hands: Fictions of Agency, Renaissance to Modern. Stanford: Stanford UP, 1999.

Shuttleton, David E., “'Please put a date to your letters ...': The Textual Evidence for Dr William Cullen's Management of His Epistolary Practice." Journal for Eighteenth-Century Studies 39.1 (2014): 59-77. Web. 7 Sept. 2015.

Tallis, Raymond. The Hand: A Philosophical Inquiry in Human Being. Edinburgh: Edinburgh UP, 2003.

Warne, Vanessa. "Artificial Leg." Victorian Review 34.1 (2008): 29-33.

—. "To Invest a Cripple with Peculiar Interest': Artificial Legs and Upper-Class Amputees at MidCentury." Victorian Review 35.2 (2009): 83-100.

Wild, Wayne. Medicine-by-Post: The Changing Voice of Illness in Eighteenth-Century British Consultation Letters and Literature. New York: Editions Rodopi, 2006.

Yuan, David D. "Disfigurement and Reconstruction in Oliver Wendell Holmes's 'The Human Wheel, Its Spokes and Felloes." The Body and Physical Difference: Discourses of Disability. Ed. David T. Mitchell and Sharon L. Snyder. Ann Arbor: U of Michigan P, 1997. 71-88.

Zemka, Sue. "1822, 1845, 1869, 1893, and 1917: Artificial Hands." BRANCH: Britain, Representation and Nineteenth-Century History. Ed. Dino Franco Felluga. Extension of Romanticism and Victorianism on the Net. Web. 7 Sept. 2015. 